\title{
Akıllı Kalite Kontrol Kameraları ve Karşılaştırılması
}

\author{
Emre Demirkiran $^{1 *}$ \\ $\mathbf{1}^{*}$ ESITT Elektronik Sistemler İmalat ve Tic. Ltd. Şti, İstanbul, Türkiye, (ORCID: 0000-0002-6574-0371), emred@esit.com.tr
}

(1st International Conference on Applied Engineering and Natural Sciences ICAENS 2021, November 1-3, 2021)

(DOI: 10.31590/ejosat.1009203)

ATIF/REFERENCE: Demirkıran, E. (2021). Akı1lı Kalite Kontrol Kameraları ve Karşılaştırılması. Avrupa Bilim ve Teknoloji Dergisi, (28), 627-629.

\section{$\ddot{O} z$}

Üretimine başlanan ürünlerde üretim sırasında ve sonrasındaki denetimlerde tespit edilemeyen hatalar üretim hattında üreticiler için büyük kayıplara neden olarak müşteri memnuniyetinde negatif etkiler yaratmaktadır.

Bu etkiler üreticileri kalite kontrol faaliyetlerinin insan gücünden uzak yöntemler aramaya yöneltmiştir.

Endüstride üretim boyunca akıllı kameraların kullanıldığı bir kalite kontrol sistemi, herhangi bir algoritma mantığıyla üretilmiş olan ürünler için insan gücüne kıyasla kalite kontrollerini hızlı ve kusursuza en yakın değerlerde yapabilmektedir. Bu sistemler ürünlerin üretim zamanı ve maliyetini düşürerek, üretim kalitesini arttırmaktadır.

$\mathrm{Bu}$ çalışmada, üretim hatlarında gitgide değer kazanan kalite standartlarının yakalanmasında etkin rol oynayan yapay görme tabanlı akıllı endüstriyel kameraların faaliyetleri açıklanmış olup uygulama açısından en uygun sistemin üretime olan etkisi üzerinde durularak, akıllı kameraların kullanıldığı kalite kontrol sistemlerinin üretici firmaya kazandırdığı avantajlar belirlenerek sonuçları tartışılmıştır.

Anahtar Kelimeler: Akilli kameralar, Kalite kontrol, Yapay görme

\section{Smart Quality Control Cameras and Comparison}

\begin{abstract}
Errors that cannot be detected during and after production process cause great loss on the production line for the manufacturers and create negative effects on customer satisfaction.

These effects have led manufacturers to seek new methods of quality control activities apart from manpower.

A quality control system, in which smart cameras are used throughout the production in the industry, can perform quality controls quickly and closest to the perfect values, compared to manpower, for products produced with any algorithmic logic. These systems increase the production quality by reducing the production time and cost of the products.

In this study, the activities of artificial vision-based smart industrial cameras, which play an active role in catching quality standards that are gaining value in production lines, are explained, and the effects of the most suitable system in terms of application on production are emphasized, the advantages of quality control systems using smart cameras are determined, and the results are discussed.
\end{abstract}

Keywords: Smart Cameras, Quality Control, Machine Vision

\footnotetext{
*Emre DEMIRKIRAN: emred@esit.com.tr
} 


\section{Giriş}

Müşteri memnuniyeti odaklı pazar ekonomisinde ürünlerin hatasız olarak piyasaya sürülmesi son derece önemlidir. Bunu sağlamanın en iyi ve etkili yolu da üretim aşamasında yapay görme sistemlerinden yararlanmaktır.

Yapay görme sistemlerinin kullanılması ürün üzerinde yapılan gerçek zamanlı denetimlerin hızında artış, doğruluk ve güvenilirlik açısından büyük avantaj sağlamaktadır. Ayrıca hatalı üretimin tespit hızı açısından insanın fazlaca üstünde anlık karar verme yetisi olan yapay görme sistemleri üretkenlik artıŞ potansiyeli sebebiyle de oldukça cazip görünmektedir. Bu yüzden klasik üretim sistemleri yerini bilim ve teknolojinin gelişmesi ile doğru orantılı olarak büyüyen ak1llı otomasyon sistemlerine birakmaktadır.

İnsan gücünün kullanıldığı üretimde işlem sürelerinin uzun olmas1, konsantrasyon süresinin k1sitlı olması, hata pay1 olanağının fazla olması üreticileri otomasyon sistemlerine yöneltmek zorunda bırakarak, otomasyon sistemlerinin her geçen gün değer kazanarak geliştirilmesine sebebiyet vermiştir.

Fiziksel detayların fazla olduğu ve üretim hızının da yüksek olduğu kalite kontrol uygulamalarında insan gücünün hata payı imkanı akıllı kameralardan oluşan bir denetime göre çok daha fazladır. Endüstriyel kameralar etrafında inşa edilen görüntü işleme sistemleri otomatik üretimde vazgeçilmez bir bileşendir. İmalatın tüm aşamaları boyunca, ham madde ve kusur tespiti ile kalite güvencesine kadar, yüksek verimlilik ve s1k1 kalite standartlarının elde edilmesinde rol oynayan vazgeçilmez bir üretim parçasıdırlar.

Endüstri 4.0, yeni üretim şekilleri ve endüstriyel üretim içindeki organizasyonu ifade eder. Bunun temelini, geniş ağ ve veri iletişimiyle elde etmektedir. Asıl hedefi, detaylı veri toplama ve doğru bilgi alışverişi üzerine kurulu olup daha güçlü özelleştirilmiş ve verimli bir üretim ortaya çıkartmaktır. Endüstriyel uygulama alanlarından biri olan hatalı ürünlerin üretim alanında tespit edilmesi üzerine yapılan bu araştırmada uygulanan yöntemi iki ana başlıkta inceleyebiliriz. Bunlar; kalite kontrol yapilacak uygulamadaki hatasız kabul edilen referans görüntü ve bu görüntüye kıyas yapılarak hatanın tespit edildiği referans görüntüye göre hatalı olan görüntüdür. Referans görüntü daima bellekte saklanarak diğer görüntülerle kıyaslanıp sürekli bir denetim yapılır.

Sistemde çıkış olarak bize geri dönüş, referans görüntünün diğer görüntülerle kıyaslanması sonucunda oluşan ve hatalı üretimi görmemize olanak sağlayan görüntü bulunur. Akıllı kameralar için doğru görüntüyü almamıza sebep olacak uygun ortamın hazırlanması sonucunda alınan görüntü, oluşturulan algoritma üzerinde gerekli karşılaştırmaları tamamladıktan sonra hatalı bölgeleri belirleyip üretimin hatasız devam etmesini kolaylaştırır.

$\mathrm{Bu}$ çalışmada endüstriyel akıllı kalite kontrol kameraları üzerinde durularak, akıllı kameraların üretime ve üreticiye olan katkıları anlatılmış olup, sonuçları birbiriyle kıyaslanmıştır.

\section{Materyal ve Metot}

\subsection{Görüntü İşleme Teknikleri}

Görüntü işleme tekniklerinde genel amaç bir görüntüden elde edilen analiz sonucunda sadece ayıklanması istenilen bilgilerin değerlendirilmesidir. Görüntü işleme yazılımları endüstride kalite kontrol alanında çeşitli ölçüm, kontrol yada belirli bir otomasyon mantığında çalışan sistemlerde hızlı ve kararlı bir karar mekanizmasının oluşmasını sağlar. Yaygın olarak kullanılmakta olan görüntü işleme opsiyonları; görüntü filtreleme, örnekleme, sınıflandırma, özellik ayıklama işlemlerinden oluşur.

Bir görüntü işleme yazılımında referans olarak belirlenen doğru görüntünün, diğer analiz edilen görüntülere göre kıyaslanması sonucunda oluşan farklar üretimin hatalı olduğunun göstergesidir. Fakat bu kıyaslamaların yapılması kameralar için doğrudan olmamaktadır.

Akıllı kameralarda görüntü işleme; o anlık kıyaslama yapılacak fotoğrafin analiz edilmesi için gereksiz detayların ayrıştırılmasında yardımcı farklı filtreler kullanarak oluşur. Örneğin bir seri üretim bandındaki ürünlerin kıyaslanarak hatalı ürünlerin banttan ayrılması işlemi kamera tarafinda görülen renkli görüşün gri skala sonucunda tek renge indirgenerek diğer istenilen ayrıştırmanın yapılabilmesi tek renk üzerinden devam etmelidir.

Görüntülerin kıyaslanması ile hata tespitini kamera tarafındaki referans görüntünün öğrenilmesi aşaması ve sonrasında gelen karşılaştırmalarda hep ilk öğrenimini gerçekleştirdiğimiz referans görüntüyü kullanarak denetiminin yapılması olarak iki bölümde inceleyebiliriz.

Akıllı kameralar ile yapılan kalite kontrol, endüstride farklı dallarda hakimiyetini devam ettirerek kendini geliştirmeye devam etmektedir. Örneğin cam ve seramik sektörü, ülke ekonomisi için temel endüstrilerden biridir. Türkiye cam eşya üretiminde dünyada ilk üçe girerek varlığını ispatlamıştır. Bu nedenle rekabet koşulları gereği olarak kalite kontrol, üretimde önemli bir yer almaktadir.

Akıllı kalite kontrol utgulamaları; seramik ve benzeri parlak yüzeylerde, otomotiv sektörüne yönelik parça kontrolleri ve metal yüzeylerdeki deformasyon kontrolü, paketleme ve ambalaj sektörüne yönelik barkod okuma ve ürünlerin müşteriye ulaşmadan önceki son kontrollerinin yapay görme sayesinde kontrolü gibi bir çok alanda yarar sağlayan bir teknolojidir.

\subsection{Kenar Algilama}

Görüntü işlemede önemli bir yere sahip konulardan biri olan kenarlar genellikle güçlü zit yoğunluklara sahip alanlardır. Kenarlar, algoritmasını oluşturduğumuz mantık üzerinde ürünlerin tespit edilmesini kolaylaştırmakta ve sınırlarını ortaya çıkartmakta önemli bir rol oynar. Dolayısıyla elde edilen görüntünün bir çok fiziksel özelliği algılanan kenarlar sayesinde açığa çıkarılarak öğrenilebilir. Görüntüleri temel olarak renkli görüntüler ve gri seviyeli görüntüler olarak ikiye ayırabiliriz.

$\mathrm{Bu}$ tanımlamalara uygun olarak görüntelerdeki kenar bulma yöntemleri hangi renk uzayında çalışılacağında bağlı olarak değişkenlik gösterir. Renkli görüntü yakalama sistemleri RGB (R; kırmızı, G; yeşil, B; mavi) olarak bilinen renk uzayında çalışmaktadır. Aynı parlaklıkta farklı görüntüler için kenar bulma renkli görüntülerle sağlanabilir. Buradan kıyasla gri tonlarındaki 
görüntülerde tanımlanamayan ek özellikler renkli görüntülerden bulunabilir.

Elde edilen görüntülerde kenar tespitinin yapılabilmesi, ürünlerin fiziksel özelliklerinin tanınması, sınırlarının belirlenmesi açısından büyük öneme sahiptir. Kenar algılama amacıyla hazırlanan yazılımlarda elde edilen fotoğrafların ilk olarak gri tonlu hale getirilmesi daha sonra istenen ayrıştırmanın yapılması amaçlanır. Yaygın olarak kullanılan kenar tespiti algoritmaları Sobel, Prewitt, Canny ve Laplace off gauss'dur.

Şeklil 2.2a ve Şekil 2.2b'de gösterilen resimde laser kaynak mekanizmasına bağlanan Cognex smart kamera aracılığıyla kaynak yapılacak bölgenin tespiti sağlanmaktadır.

Oluşturulan algoritmada kaynak yapılacak alandaki çemberin bulunması; referans görüntüde tanımlanan Edge'ler sayesinde gerçekleşmektedir. Kamera tanımlanan Edge noktalarına geldiğinde çemberin fiziksel özelliklerini çıkartarak konumunu kaydetmektedir. Laser kaynak makinesi konum olarak kaynak yapılacak alana geldikten sonra laser programını başlatıp programı sıradaki kaynak yapılacak parçalar için aynı mantıkta çalışmaya devam etmektedir.

\subsection{Kalite Kontrol ve Hatalı Ürün Tespiti}

Üretim denetiminin akıllı kameralar kullanılarak yapılması, ürünlerin fiziksel özelliklerinden faydalanılarak oluşturulan algoritmanın gerekli bölgelerinin tanınması sonucunda birbirinden kıyaslanması ile gerçekleşir.

Yapay görmede nesne tanımlaması; tıpkı insalarda olduğu gibi önceden öğrenilen bilginin sürekli karşılaştırma yapılması ile gerçekleşir. Önceden öğrenilen bilgiler sistemin bildiği bir

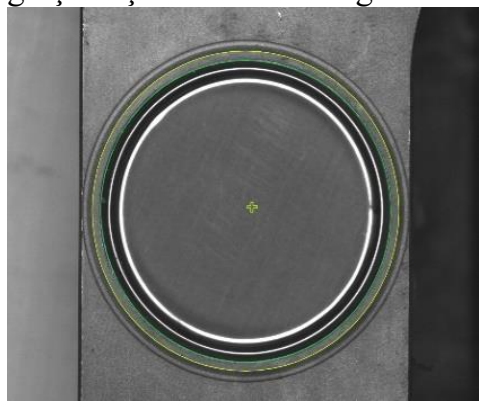

Şekil 2.2a

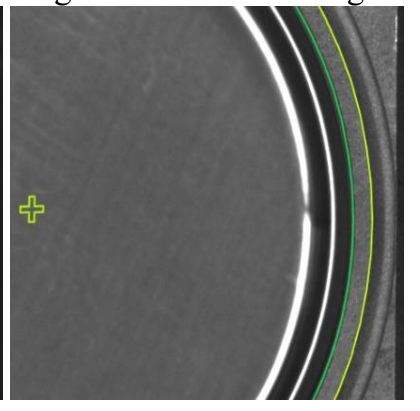

Şekil2.2b

\section{Araştırma Sonuçları ve Tartışma}

Üreticilerin çalışmalarına değer katabilecek, üretimde verimliliği arttıracak bilgisayar tabanlı yapay görme sistemleri, geliştirilen çözüm faaliyetlerine entegre edilerek üretim kalitesini arttırarak üretime değer katmaktadır.

Üretimde otomasyon faaliyetlerinin önemi, teknolojinin gelişmesi ile doğru orantılı olarak gelişmektedir. Ürünler arasındaki istenmeyen maddeler, deforme olmuş ürünler gibi fiziksel yönüyle sorun teşkil eden ürünler kameraya dayalı sistemlerde kolayca tespit edilebilir.

Elde edilen verilere göre üretimde yapay görme sağlayan akıllı endüstrinin, kalite problemlerinde insan gücüne kıyasla daha başarılı bir sonuç ortaya çıkardığını, hata payı değerlerinin düşük olduğunu, zaman açısından işletmeye verilen kazancın yüksek olduğu bilinmektedir. veritabanında saklanır, yeni öğrenilen yani kıyaslanması yapılacak bilgiler ise referans bilgiler ile karşılaştırılarak nesnelerin fiziksel özellikleri arasındaki farkları ortaya koyarak, daha önceden öğrenilmemiş bilgileri açığa çıkarır.

Yapay görme sistemlerinden yararlanılarak oluşturulan, ürünlerdeki hatalarının belirlenmesi ve hatalı ürünün diğerlerinden ayrıştırılması üzerine kurulan üretim prosesinde verimlilik, duyulan güven bakımından üreticilere oldukça avantaj sağlamaktadır.

Kameralı kontrol mekanizmasındaki üretimin; denetimi yapılacak her ürünü yakından inceleme firsatı kolaylığı ve hiçbir ürünün hatalı olarak gözardı edilmediğinin bilinmesi üreticilerede büyük rahatlık sağlamaktadır.

Kameralı kontrol hatalı yapılan işlerin tekrarlanması yüzünden oluşan verim kaybını tamamen ortadan kaldırıp, ürün israfinı azaltarak genel proses iyileştirilmesine yardımcı olur. Bu da, daha az sayıda hatalı ürün ve çalışan personelin diğer işlere odaklanması anlamına gelir. Üretime sağlanan verimlilik ve güven, tüketiciler yönünde marka imajını arttırarak yüksek kalitede ürünlere ilişkin itibarın korunmasında fayda sağlar.

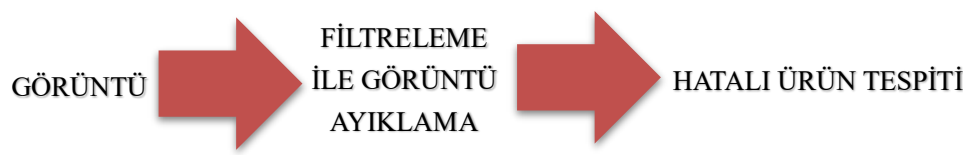

Yapay görmenin temel amacı üretimde karşılaşılan operatör kaynaklı veya diğer üretim hatalarını hızlı bir şekilde tespit ederek iş gücü ve tasarrufu etkin bir şekilde ortaya koymaktır.

Sonuç olarak üretimdeki akıllı kameralar mekanizmasında kalite kontrolü sağlanan ürünler kalite standartları açısından faaliyetlerinin, başarıyla sonuçlandığı görülmüştür.

Yapay görme teknolojisine bağlı olarak geliştirilen otomasyon sistemleri uygulamalarının sayısının her geçen gün artması, toplumsal yararın artması yolunda bizlere katkı sağlayacaktır.

\section{Kaynakça}

[1] Büşra.K. Kalite Kontrol Faaliyetlerinde Yapay Zeka kullanımı htps://dergipark.org.tr/tr/pub/yalovasosbil/issue/27392/289024 (Erişim Tarihi: 28.12.2016)

[2] Özcan, A. 2016. Yapay Görme Sistemlerinin Yatırım Kararlılığının Değerlendirilmesi İçin Bir Model Önerisi. Maltepe Üniversitesi, Sosyal Bilimleri Enstitüsü, Doktora Tezi, İstanbul. 